ÉGYPTE monde arabe

\section{Égypte/Monde arabe}

$14 \mid 2016$

Le Soudan, cinq ans après l'indépendance du Soudan du Sud

\title{
Dismantling Processes in the Sudanese Public Health Services Sector
}

The Case of Dr Abbo's Fistula Centre

Hind Mahmoud Youssef Hussein and Alice Koumurian

\section{OpenEdition}

Journals

Electronic version

URL: https://journals.openedition.org/ema/3598

DOI: $10.4000 /$ ema.3598

ISSN: 2090-7273

\section{Publisher}

CEDEJ - Centre d'études et de documentation économiques juridiques et sociales

Printed version

Date of publication: 21 October 2016

Number of pages: $169-186$

ISBN: 2-905838-88-4

ISSN: $1110-5097$

\section{Electronic reference}

Hind Mahmoud Youssef Hussein and Alice Koumurian, "Dismantling Processes in the Sudanese Public Health Services Sector", Égypte/Monde arabe [Online], 14 | 2016, Online since 21 October 2018, connection on 07 July 2022. URL: http://journals.openedition.org/ema/3598 ; DOI: https://doi.org/ 10.4000/ema.3598 


\title{
Hind Mahmoud Yousif Hussein and Alice Koumurian
}

\section{DISMANTLING PROCESSES IN THE SUDANESE PUBLIC HEALTH SERVICES SECTOR}

\author{
THE GASE OF DR ABBO'S FISTULA CENTRE
}

\section{ABSTRACT}

\begin{abstract}
The idea for this paper was inspired by the discovery of the destruction of Dr Abbo's Fistula Centre in 2015. Why was this centre of international renown destroyed? Our assumption was that the decision was related to dismantling processes and liberalization policies in the Sudanese public health services sector. The main sources for our analysis consist of various interviews conducted with health practitioners and stakeholders during February and March 2016.
\end{abstract}

\section{INTRODUCTION ${ }^{1}$}

"All of a sudden, I heard that the centre was going to be destroyed (...)" said Dr Abbo when we met him in February 2015. "I said to Dr Mamoun [Mamoun Humeida, the Minister of Health of Khartoum State], this centre is

1 Hind Mahmoud would like to thank Dr. Abbo for allowing her the recent opportunity to interview him about the dismantlement of the fistula centre that he founded. This gave her the privilege to update and revisit previous data related to the relationship of socio-economic status and its link with the occurrence of fistula. On the basis of this data the present article offers a new perspective on the link between the demolition of this centre and the state of public health services. 
not for Sudan, it is for the whole world, all of Africa (...). This building is known all over the world".

Ten years ago, while doing her fieldwork for her Master's thesis on the socio-economic impact of obstetric fistula on Sudanese women, Hind Mahmoud spent a great deal of time with the patients and doctors at Dr Abbo's Fistula Centre at Khartoum Teaching Hospital. At the time, she was studying gender issues for her Master's Degree at the Ahfad University for Women.

Dr Abbo's Centre, which was partly funded by UNFPA², specialized in the treatment of fistula, and began operating in the early 1970s. It was known for having "one of the longest-running fistula programs on the African continent" 3 and was a place where on the one hand, women with fistula could stay and be operated on by qualified practitioners, and on the other, doctors could be trained in fistula surgery ${ }^{4}$. When Hind Mahmoud was told about the destruction of the centre during $2015^{5}$, following a decision by the Ministry, she was unable to understand why this had happened, since the Centre was crucial to women's well-being.

This paper was inspired by the discovery of this destruction, and asks why a centre of international renown ${ }^{6}$, an international training centre for fistula surgeons, which followed the training manual developed by the FIGO (Fédération Internationale de Gynécologie et d'Obstétrique) and the ISOFS (Société Internationale des Chirurgiens Obstétriques de la Fistule), should be destroyed. Unlike Hind Mahmoud's Master's thesis, the main focus of which was the socio-economic impact of obstetric fistula, this paper addresses the institutional aspects of the running of Dr Abbo's Centre.

Our assumption was that the decision to destroy the Centre was related to a dismantling process and to the implementation of liberalization policies in the Sudanese public health services sector, which are themselves linked to a more general context of liberalization in the Sudanese economy.

In terms of scientific literature, liberalization in Sudan is a pretty well-documented topic. Babiker has explained that "Sudan started to experiment with adjustment programs at the turn of the 1970s, and since then has continued

2. The United Nations Population Fund.

3. Fistula Foundation.

4. As Khalil writes, "Dr. Abbo Hassan Abbo is one of the leading international experts in the field (he was given a lifetime achievement award by the International Urogynecological Association in 2009), and he established this centre as an extension of Khartoum Hospital's fistula ward in 1989. (...) All registrars training in obstetrics and gynecology in Sudan must work a shift at the centre" (Khalil, A., 2011). 5. As we explain further below, after its destruction, Dr Abbo's Centre was replaced by a mere ward at Khartoum Teaching Hospital.

6. Source: WAHA. Dr Abbo's Fistula Centre also used to be one of UNFPA's ninety-two partners in its global campaign to end fistula launched in 2003 (http://www.endfistula. org/campaign). 
implementing one form of adjustment policy or another; in the 1990s, however, the government followed self-imposed adjustment policies without the support of any international institution" (Babiker 2016: 14). Ahmed and Marchal write: "in February 1992, the economic policy changed drastically and took a truly neo-liberal turn. It used the most radical recipes of the IMF without any of the corrective measures that are usually implemented to mitigate the social costs of structural adjustment" 7 (Ahmed \& Marchal, 2007: 32). Ahmed and Marchal explain that the liberalization policy was put into effect at several levels: in 1994, a federation was created that allowed new administrative entities to be required to bear the costs of essential public services (health, education, and local infrastructure), and the government also gradually reduced subsidies for basic goods. Finally, it dismantled the para-public sector through extensive privatization policies (Ahmed \& Marchal 2007: 32-33).

Although liberalization policies in the Sudanese public health services sector are a central component of this paper, they are not the only issue to be addressed, as the analysis that follows is also intended to deal with the difficult issue of fistula in Sudan.

This paper, which is a collaborative work between Hind Mahmoud and Alice Koumurian, therefore consists of three main sections. In the first, we explain our research method, and show that fistula is a challenging research topic. In the second, we present the case of Dr Abbo's Fistula Centre from its creation to its destruction. In the third, we connect the case of the destruction of Dr Abbo's Fistula Centre to the wider dismantling process that is assailing the Sudanese public health services sector.

\section{RESEARCH METHOD AND RESEARCH CHALLENGES}

In addition to a review of the existing literature on liberalization policies in Sudan (Ahmed \& Marchal 2007, Babiker 1996, Mann 2014), the main source for our analysis is made up of various interviews conducted with health practitioners and stakeholders during February and March 2016.

Our original intention was to limit our fieldwork to a single interview with Dr Abbo, the founder of the Centre, from whom we hoped to learn more about the reasons behind its destruction. We managed to secure an interview with him through personal connections, but this was no easy matter, given his great anger following the destruction of his Centre. Initially, he refused to meet with us; however, when one of his friends convinced him of the academic merit of exposing the matter, he agreed to give us two hours of his time. We were grateful for this, because he had refused to attend the OB-GYN

7. Translated from French by the authors. 
specialists conference that had taken place on 18-22 February 2016, just a few days before our meeting.

During this interview, which took place at Dr Abbo's home, due to his reduced mobility, Dr Abbo shared many important aspects that we will discuss in depth in this article, but he repeatedly refused to give us a clear explanation of the Khartoum State Ministry of Health's decision to destroy the Centre. Because of the questions that went unanswered during this interview, and also because we wanted to explore the issue of liberalization policies in the Sudanese public health services sector further, we decided to carry out several other interviews - both formal and informal - with health practitioners and stakeholders.

Several requests for interviews were initially turned down, however, as was the case with the new male coordinator of the new fistula ward. We overcame this obstacle by approaching UNFPA's representatives in Sudan, as this UN agency had been one of the contributing donors to Dr Abbo's Fistula Centre. When we met them, they agreed to organize a visit to the new fistula ward, which allowed us to meet its coordinator, and two formal interviews were eventually organized with him. In terms of our research method, having a Sudanese researcher helped gain access to the new ward. Conversely, having a foreigner involved implied being potentially perceived as a member of the staff of one of the few international NGOs based in Sudan, whose access is strictly controlled - even more so when it comes to visiting public institutions and services. For this reason, Alice Koumurian's visit to the new ward had to be organized under the umbrella of UNFPA, and she was only able to enter by arriving in a UNFPA car (we should specify that the entrance gates are controlled by guards). At the same time, once the meeting with the coordinator of the new ward was under way, the foreigner was somehow perceived as being a potential donor. The UNFPA representative emphasized this point when introducing Alice Koumurian to the coordinator, although Alice Koumurian herself tried to explain that she did not have this power in her hands.

In addition, Hind Mahmoud obtained a formal interview with the coordinator who had been in office at the time of the destruction of Dr Abbo's Centre. Initially, this former coordinator asked to be provided with a letter from CEDEJ Khartoum on its headed notepaper. This person also originally claimed that the Ministry of National Health had to give permission for publication of the former coordinator's words.

Three open-ended interviews with patients and some relatives took place during our visits to the new ward after the destruction of Dr Abbo's Centre. An informal interview was also conducted with a fistula surgeon who had left the Centre and is currently working abroad as an international surgeon. We also informally interviewed an international health consultant who was working for the Ministry of National Health in Sudan.

Besides the difficulty in obtaining some of these interviews, the lack of availability of data from the new ward - on the success rate of fistula surgery, 
for example - presented an additional research challenge. We were told that due to the move and changes in the management team, organizational and logistical problems were still being faced, and that the old files had still not been classified.

\section{THE ISSUE OF FISTULA IN SUDAN: A CHALLENGING RESEARCH TOPIC}

In Sudan, where "great numbers of women suffer from obstetric fistula as a result of childbirth" (Mahmoud 2005), the issue is undeniably a serious one. But what exactly is obstetric fistula? Technically, it "is a hole between the vagina and rectum or bladder that is caused by prolonged obstructed labor, leaving a woman incontinent of urine or feces or both" ${ }^{\prime}$. Depending on where it forms, a fistula can be called either "vesicovaginal" or "rectovaginal". As for the causes of obstetric fistula, they are fairly well known: according to the UNFPA, "lack of access to obstetric care, traditional harmful practices of child marriage where the body of a young girl is often not mature enough for safe deliveries and female genital cutting" are among its main causes.

There is also another form of fistula: the iatrogenic fistula. Unlike obstetric fistula, which only occurs during childbirth, iatrogenic fistula ${ }^{9}$ is the result of medical malpractice that can occur accidently during surgery that may be related or unrelated to childbirth.

In most cases, fistula can be cured by surgery. In some rare cases of inoperable fistula, however, the doctor can perform a urinary diversion, which may result in numerous complications - such as acid-base disturbances, renal infection and carcinoma of the colon - that shorten the patient's span of life. When we met him, Dr Abbo explained to us that in spite of the fact that he used to tell his patients that they could not expect to live for more than seven years after an operation such as this, this information usually did not prevent them from requesting urinary diversion surgery, which shows the extent of their desperation.

As Hind Mahmoud explains in her Master's thesis, "one of the most important cultural factors contributing to the prevalence of obstetric fistula in Sudan is early marriage". Indeed, young pregnant women may experience obstruction during the childbirth due to the width of their pelvises: "the girl still has $4 \%$ of her height to gain and her pelvis will only be $82-88 \%$ of its fully grown size (ASI 1994)" (Mahmoud 2005). If an unborn child becomes stuck, it will result in a lengthy delivery that can take up to three or four days, or even a week in some cases. This usually results in a stillborn baby and, for the woman

8. Fistula Foundation.

9. Iatrogenic fistula can be caused by ischemic damage or injury caused during a caesarian section or an emergency hysterectomy. 
in the formation of a fistula. In some circumstances, the woman may also die from internal bleeding.

Despite its seriousness, Mahmoud states (2005) that "fistula is a relatively hidden problem because it affects the most marginalized members of society". On the issue of marginalization, one might even argue that the problem of fistula acutely reveals the existence of serious imbalances in Sudan. Not only is fistula a gender and class issue, but it is also a sign of regional inequalities, as is the case with Darfur, which is deeply affected by "the largest numbers of fistula sufferers" ${ }^{10}$. In addition, the fact that it affects the female sexual organs inevitably adds to its status as a "taboo".

Fistula therefore emerges as a hidden, shameful problem on which scientific information is lacking. As Mahmoud claims, "reliable data on obstetric fistula in Sudan are scarce, sometimes alarmingly so, and often inaccurate, as the full extent of the problem has never been mapped"11 (2005). A scientific approach to the issue of fistula in Sudan therefore addresses a gap in the literature, in particular in that dealing with Sudanese women's health issues: indeed, there is a striking difference between the small number of writings on fistula and the abundant literature ${ }^{12}$ on the practice of female genital mutilation (FGM). "Nearly every female anthropologist in Sudan has written something on this topic", as the American anthropologist Ellen Gruenbaum has noted. Thus, compared with the "massive international movement" 13 (Gruenbaum 2015) that has mobilized around FGM, less has been done and written about obstetric fistula. Nonetheless, it should be noted that the two issues are indirectly connected, since FGM might be considered to be a secondary cause of fistula. As Khalil explains it, "pharaonic (infibulation type) FGM is relatively common in Sudan, and in these cases healing with fibrosis may occur, leading to a delay in the second stage of labor, causing obstruction"14 (2011). This obstruction is then responsible for the formation of fistula.

As researchers, the need to address this issue scientifically and to overcome the taboo surrounding fistula seemed obvious to us, but the research process has been neither easy nor consensual. For anyone discovering the issue of fistula - as was the case for one of the researchers in the team - looking at pictures or listening to technical descriptions of fistula is inevitably an unpleasant experience. In the same way, the personal stories of fistula patients can be very disturbing - or even traumatic - to listen to.

10. UNFPA, 2014.

11. UNFPA's representatives told us precisely the same thing when we interviewed them: they lack accurate data on fistula in Sudan.

12. Abusharaf, 2007; Toubia, N., 1994; Boddy, J., 2007; El Dareer, A., 1982.

13. Gruenbaum, E., 2015.

14. Khalil, A., 2011. 
This point can be illustrated by a description of a scene that took place at Khartoum Hospital, in the newly-created unit dedicated to the treatment of fistula after the destruction of Dr Abbo's Fistula Centre. One by one, we visited the rooms where women were either waiting for their surgery or recovering from it. Two women approached us: they were a mother and her daughter. The mother told us that her daughter's fistula had been caused during sexual intercourse with her husband. Her daughter began to cry, her head down. The surgeon explained that the woman, who was infibulated, had most likely been "opened" by her husband with a knife during their first intercourse: he had torn everything, which resulted in the formation of fistula, although he made it clear that this was not the most frequent causal factor. Irrespective of the origin of the formation of a fistula, however, these women's personal stories, as seen through both the causes and the consequences of fistula, are all very difficult to hear, and must be even more harrowing to experience.

Among our research team, Hind Mahmoud, who is Sudanese, was more familiar with the topic since, as we have already mentioned, it is a very serious issue in Sudan. Her originally cursory knowledge was deepened when she did her Master's thesis on the subject and spent time at Dr Abbo's Centre while conducting her fieldwork. However, since fistula affects women of low socio-economic status most widely, she has always been personally detached from the problem of fistula due to her socio-economic advantage. Alice Koumurian, on the contrary, only discovered fistula in the course of this stretch of fieldwork; she had not been exposed to it in Europe, where fistula is rare ${ }^{15}$.

\section{FROM AN INTERNATIONALLY RENOWNED CENTRE TO DESTRUCTION IN 2015: THE CASE OF DR ABBO'S FISTULA CENTRE}

As we mentioned earlier, our field research began with a meeting with the 88-year-old Dr Abbo himself, who agreed to welcome us into his home. Dr Abbo was an obstetrician/gynaecologist (OBGYN) and founder of Dr Abbo's Fistula Centre, which was named after him. Dr Abbo opened the discussion with a detailed medical explanation of obstetric fistula. He summed it up thus: "fistula is due to pressure" during delivery. He continued: "pressure will lead to ischemia; ischemia will lead to a loss of blood supply; a loss of blood supply will lead to necrosis; and necrosis is followed by sloughing". He then showed us a series of pictures on his computer to help us understand. While explaining the technical aspect of obstetric fistula, Dr Abbo also stressed the serious psychological effects fistula has on a woman: "she is not needed in the community"; "usually, she cannot eat with her family and

15. Cowgill, K. D., Bishop, J., Norgaard, A. K., Rubens, C. E., \& Gravett, M. G., 2015; Wall L.L., 2012. 
she cannot drink with her family, because she smells of urine". Another doctor, who reported to us that practitioners often speak of "social death" after the formation of fistula, corroborates Dr Abbo's statement. In fact, fistula affects women's social lives deeply by causing constant incontinence. This rejection on the part of the family can lead to serious psychological problems: a woman with fistula "might get (sic) mad", to use Dr Abbo's own words.

As he told it, Dr Abbo became interested in the fistula problem during the time when he was a registrar at the Omdurman Medical Hospital. He witnessed how fistula patients were "completely neglected by all doctors". When he obtained his medical qualification in 1963, he chose to include the treatment of fistula as part of his specialization. After six months of training in Ethiopia with two Australian doctors who were treating fistula there, Dr Abbo returned to Sudan, where he started operating in a very poorly-equipped ward. It was during this period that he met a French nun, Sister Emmanuelle, who later became a central figure in the construction of $\mathrm{Dr}$ Abbo's future Fistula Centre. As Dr Abbo told us, not only she did provide the funding to build the Centre, but "she brought the people" and "supervised everything". Later on, after Sister Emmanuel had returned to France, Dr Abbo requested and obtained the help of the American "Black Women's Forum" (Los Angeles). With the fund (25,000 USD) the organization gave him - "a very big fund at that time!" - Dr Abbo managed to finish construction of his Centre, and some time thereafter, Sister Emmanuelle returned to Sudan and provided the Centre with the necessary equipment (beds, instruments, operating theatres, etc.). As Dr Abbo put it, "the building was fantastic".

Since Dr Abbo did not have a nursing staff working for him, he told us that he used to train his patients in nursing or even fistula surgery. He seemed particularly proud of this aspect: "the most beautiful thing I have done in my life: I trained the patients". Dr Abbo made a point of managing his entire staff himself. He also succeeded in attracting young doctors who were willing to be trained in fistula surgery and to assist him in his work. The Centre also gradually acquired a certain reputation abroad. Dr Abbo told us that he "used to go outside the country to speak about the Centre (....). I had to fly to Chad, Somaliland, Yemen. (...) The Centre started to be well known throughout the whole world. It was the second fistula centre in the whole world following the Ethiopian one".

During our discussion, Dr Abbo eventually mentioned the destruction of his centre. Although we tried several times to ask him why, according to him, the Minister of Health in Khartoum State had taken this decision, his immediate answers were "Mamoun Humeida can answer you" and "up to now, nobody knows why it was broken up". But he also told us that after the destruction, he had been contacted by the Health Minister, who said "I am not destroying it; I am moving the patients". He then explained that he did not intend to do anything about this decision: "I am getting old", "I am waiting for my day". Since the destruction of the Centre, Dr Abbo also said that he had suffered from "depression, severe depression": "I spent all my life trying to build this centre 
and [it] is now being destroyed by Mamoun". These words are echoed in a poem entitled "Eulogy of Lament and Bafflement" that he composed in reaction to the demolition of the Centre. Dr Abbo requested that this poem be read during the fistula panel at the OB-GYN specialist conference held on 18-22 February 2016 at the Khartoum Police Club, which - as we mentioned earlier - he refused to attend to show his anger at seeing his Centre destroyed. During our meeting, he shared this poem with us, as well as an article written by Mahjoub Mohamed Salih, a well-known Sudanese journalist and the founder of Al-Ayam newspaper, questioning the reasons behind the destruction.

Here is Dr Abbo's poem, entitled "Eulogy of Lament and Bafflement"16, which was written in reaction to the demolition of his Centre:

Oh Greetings, fistula centre.

May God make your existence fruitful and bless you with protection

In your vicinity we fought hardship in all its violence

and we overcame it and you were the source of this success

In your space we spent time

and through cure we wiped away tears

For Sudan you represented a symbol and a mark

for the black content and the world at large

The bulldozer refuses you eternal presence

and through oppression (it) simultaneously obliterated both history and knowledge

They destroyed you with no due consultation

because of the vast differences of opinion that would inevitably ensue

16. Translated from Arabic by Dr Azza Ahmed Abdel Aziz. Here is the original version of Dr Abbo's poem:

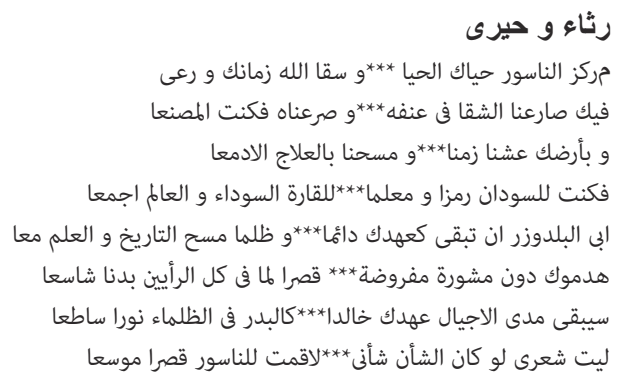




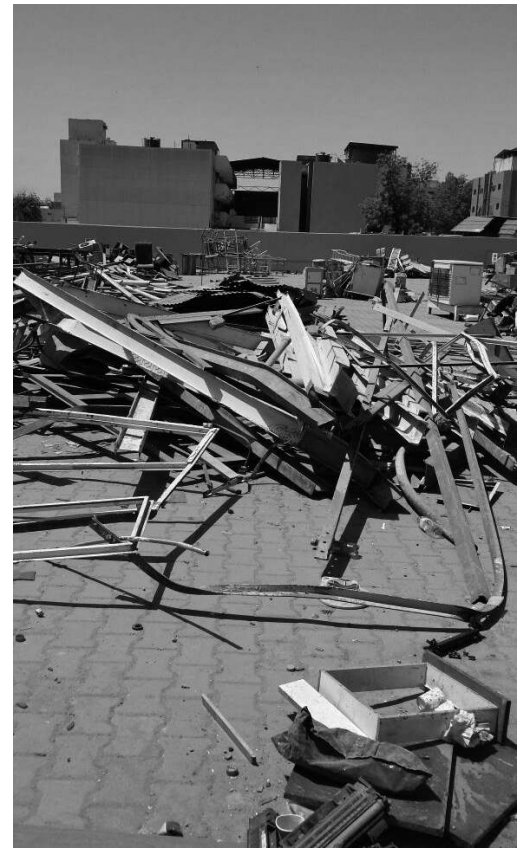

View of the remains of the old site after destructions. Hind Mahmoud, February 2016
Your legacy will endure eternally through generations

like the moon, in obscurity, emanating a brilliant light

\section{I wish that poetry were my domain}

so that I might be able to construct a homage to the fistula worthy of the stature of a palace.

Although we asked several times, Dr Abbo did not offer us a clear explanation of the decision to destroy the Centre. Similarly, when we discussed the issue with various doctors and stakeholders, it always appeared to be a highly sensitive topic, and we consistently felt that we were walking on eggshells. Some of our informants simply replied "government politics", without being more specific. Others mentioned the government's intention to build a road in the area of the Centre, which would serve as justification for its

destruction. Likewise, it was difficult to obtain a clear answer on whether or not the new place - reconstituted through a simple revamping of an old obstetric ward within a hospital - was able to provide the same capacity and quality of health care and teaching. This question also appeared to be a sensitive one.

On the topic of the comparison between Dr Abbo's Centre and the new ward, the discomfort was palpable during our meeting with the UNFPA representatives. UNFPA used to fund Dr Abbo's Fistula Centre: as one representative put it, "we invested a lot in this centre". However, in response to our questioning regarding the changes since the destruction of Dr Abbo's Centre, they replied that, "as UNFPA, we cannot say if it was bad or good". At the same time, they also contradicted themselves during our discussion when they told us that when "they took the patients to the new centre and put in the new equipment", "it was very slow", whereas later on they said that "there was no delay", and "the Ministry of Health in Khartoum accelerated [the process]".

We obtained the same conflicting statements in our interviews: while some of our informants said that everything remained the same after the destruction of Dr Abbo's Fistula Centre and relocation to the new ward, others claimed the contrary: that various aspects relating, inter alia, to the capacity of the new ward, the training of doctors, and equipment have deteriorated sharply. First, in contrast with the UNFPA representatives' assertions, other informants told us that the new ward had remained closed and that operations 
took three months to resume after the relocation to the new ward. We were also told that as a result of the interruption and relocation, access to surgery was also compromised: some women did not know that the Centre had been replaced by a ward, and therefore did not come to have the surgery they needed. As for the quality of health care, we were told that some equipment had been damaged during relocation as a result of mishandling.

Based on our own observations, the two spaces are not comparable. Firstly, the large specialized institution that was Dr Abbo's Fistula Centre has become a mere ward located at Khartoum Teaching Hospital. Secondly, unlike its predecessor, the operating theatre in the new ward does not seem to meet international standards, and fails to comply with adequate standards of biomedical hygiene. Being located on the ground floor in proximity to the main entrance to the ward, it is more likely to be exposed to dust and dirt, with the risk of contamination from the outside environment. Thirdly, in terms of capacity, the ward currently hosts 34 beds, and while, like in Dr Abbo's centre, there are still 20 pre-operative beds, the number of post-operative beds has been reduced from 20 in Dr Abbo's Centre to 12 in the new ward.

In relation to human resources, the new ward relies on only two active doctors compared with six in 2005: one retired doctor who is still practicing on a voluntary basis, and twelve nurses. This very limited medical staff is clearly indicative of a crisis, given that this type of surgery does not attract the attention of physicians who might be persuaded to join if more adequate funding were provided to facilitate the new centre's performance. While some talented doctors have left the centre, the current surgeons in the new ward remain the same as ten years ago. In addition, some of our informants also mentioned deterioration in the training of doctors in fistula surgery, which was one of Dr Abbo's pillar objectives. In addition, his Centre trained fistula surgeons who were willing to practice at facilities located in various provinces of Sudan (Kassala, El-Fasher, Zalingei, El-Geneina, and Nyala). These doctors were trained to adapt to and deal with local issues: reaching fistula patients living in remote areas, providing information on the possibility of treating fistula, and supporting and advising patients in terms of physical and psychological recovery. We harbour doubts about the capacity of the new ward to perform this function in the same way as Dr Abbo's Centre did.

With regard to our questions pertaining to the success rates of fistula surgery, we were not able to compare the situation before and after the destruction, as we could not find any statistics relating to the period since relocation.

Despite all the limitations we have mentioned above, the cost of surgery remains negligible, since today, as in the past with Dr Abbo's Centre, patients continue to receive treatment at no cost, as was confirmed by a doctor working in the new ward.

In order to provide a complete picture, we should mention another significant achievement: the creation of a vocational training centre in 2010 as part 
of the Khartoum Teaching Hospital. This centre is a joint project between the Ministry of Social Welfare and Dr Abbo's Centre. As women with fistula cannot usually return home and stay with relatives due to the stigma surrounding their condition, this fistula centre is a refuge as well as a training centre for patients: given the fact that most are illiterate, it offers them programmes for learning handicrafts, for example. The refuge is therefore a kind of ward: It is a "wagf" (donation) to Khartoum Hospital from the Presidency of the Republic of Sudan for fistula patients. The doctors decide on admissions on a case-bycase basis in collaboration with a social worker. They generally favour vulnerable patients whose circumstances do not allow them to return home (due to distance from their homes, difficulties with travelling long distances, etc.). At this moment, it is receiving food aid from an individual donor, but its future of the refuge, which is located in a prime location in Khartoum, on Katarina Street in Khartoum 2, has not yet been determined.

\section{DR ABBO'S FISTULA CENTRE: AN ILLUSTRATION OF THE LIBERALIZATION POLICIES AND DISMANTLING PROCESSES IN THE SUDANESE PUBLIC HEALTH SERVICES SECTOR?}

In an interview with the Sudan Vision daily newspaper in August 2015, shortly after the destruction of Dr Abbo's Fistula Centre, UNFPA's Sudan Representative Lina Musa declared:

UNFPA has marked Fistula Day 2015 with a high-level presence from the Government and the Italian Ambassador to Sudan and the team from the Italian International Cooperation, as the main donor to UNFPA on fistula work. The celebration was held at the Abbo Centre for Fistula Treatment, and entitled "End Fistula, Restore Women's Dignity". The event was an opportunity for government officials and donors to interact with fistula patients (both those who had been treated and those who were on the waiting list), as well as to strengthen their partnership to break the silence around the issue, secure political commitment and mobilize resources to meet the huge needs for such an expensive treatment (Sudan Vision 2015).

Firstly, when UNFPA's Sudan Representative mentions the "Abbo Centre", she is actually referring to the new ward, and not to the Centre built by Dr Abbo, as one of our informants confirmed. Disingenuously, as we also noticed during some of our interviews, the term "Dr Abbo's Centre" is still used to describe the new ward, and an old placard identifying the Dr Abbo Centre was even hung outside the new place. Secondly, given the destruction of Dr Abbo's Centre and relocation to the new ward, the "political commitment" mentioned by UNFPA's Sudan Representative was obviously neither very strong nor very reliable. 
During our fieldwork, we attempted to learn more about the causes of the destruction. Although, as we have mentioned earlier, some of our informants did suggest some explanations - such as the government's intention to build a new road on the same location as Dr Abbo's Fistula Centre ${ }^{17}$ - we were not able to gather sufficient evidence to shed further light on the exact reasons. However, our empirical observations and our review of the existing literature lead us to connect the destruction of Dr Abbo's Fistula Centre with ongoing dismantling processes - combined with liberalization policies - in the Sudanese public health services sector. The case of Dr Abbo's Fistula Centre and the construction of the new road might also be associated with the government's strategies to capitalize land (Denis 2005; Choplin \& Franck 2014). For instance, the refuge lies in a prime location in Khartoum, and could be attractive for investment.

Driven by the general economic context, the liberalization process in the public health sector has been under way for some time, and has had a significant impact. The 2009 "National Policy for the Private (For-Profit) Health Sector" issued by the National Ministry of Health admits that "the macroeconomic and sectorial reforms implemented during 1990s led, inter alia, to an exponential increase in the private health sector. While it could be a welcome sign for enhancing coverage and access, there are indications of increasing inequity and misdistribution of health services." The existing scientific literature on the issue of health policies in Sudan, while not especially abundant, is nonetheless also helpful. Babiker observes that, in the 1990s, "private hospitals increased from 9 in 1985 to 16 in 1990 and then to 40 in 1995" (Babiker, 1996: 15). As he claims, "the expansion of private health services has been encouraged by the increased demand resulting from the deterioration of the quality of the public health service" (Ibid: 16). We can see the consequences of this expansion of private health today from the very limited scope of the Sudanese public health sector. As a recent report has shown, "the public sector funds $22.34 \%$ of total healthcare resources, while the private sector share is $73.14 \%{ }^{\prime 18}$. The destruction of Dr Abbo's Fistula Centre and its relocation to a ward with a smaller capacity undeniably contributes to the reduction of the Sudanese public health services sector, as well as to the deterioration of Sudanese public health services facilities.

There is a great deal to suggest that this trend towards privatization and reductions in public expenditure was reinforced by the arrival of Mamoun Humeida as the Head of the Khartoum State Ministry of Health in 2011. As the owner of several private hospitals, he does not seem to be best placed to defend the public health services sector, and during our interviews, the issue of his conflict of interest was raised repeatedly. A newspaper article published

17. This road now exists, at the East border of Khartoum Teaching Hospital.

18. Health financing system (PHI), 2014: 29. 
in the Sudan Tribune in 2013 gives us a glimpse of the current context, starting from the period in 2011 when Mamoun Humeida took office:

Humeida's appointment as health minister attracted a wide range of opposition among specialist doctors fearing his approach, which is focused on privatizing health services. The Minister, who owns several private hospitals in Khartoum, made the controversial decision to dismantle the largest government hospital, which was located in central Khartoum and distribute its various sections to the outskirts of the capital. Doctors and activists fear that the move was intended to privatize the hospital and discontinue the free medical services. The Minister has ordered the Brain and Neurology Department to be transferred from Khartoum hospital to Ibrahim Malik and the Academic Hospitals as part of the dismantling process. One physician, who prefers to remain anonymous, said that the two hospitals lack a basic infrastructure. (...) Critics assert that Humeida was appointed to implement a plan for privatizing health services. ${ }^{19}$

This article cites the case of the Brain and Neurology department in Khartoum Hospital, but similarly, in 2013, the Ministry of Health of Khartoum State took the decision to transfer the Jafar Ibn Auf Accidents Hospital to peripheral hospitals (Academic, Bashaier and Ibrahim Malik Hospitals). As indicated in a newspaper article published in Sudan Vision:

"Specialists criticised the Ministry's retreat from an earlier agreement with the management of the hospital on the rehabilitation and maintenance of buildings and supply of medicines and equipment before transferring it to specialised centres, which indicates its intention to close the hospital.

The specialists revealed the efforts of senior bodies in the country to stop what they called destruction and drying. They confirmed their intention to submit a memorandum to the Presidency to stop the hospital's closure, noting that the hospital receives 18,000 children per month." 20

Thus, unlike with Dr Abbo's Centre, where the destruction took place without provoking any particular reaction, the case of Jafar Ibn Auf Hospital resulted in significant protests from doctors and patients' families that eventually lead to the hospital's being kept going.

In an article published on the African Arguments website, Nesrine Malik, a Sudanese-born journalist based in London, also wrote very clearly about the

19. Sudan Tribune, 9 July 2013, Khartoum State Health Minister Assaulted by Medical Doctor.

20. Sudan Vision, 2013. 
health services dismantling approach adopted by the Ministry of Health in Khartoum State:

(...) he [Mamoun Humeida] has been accused of closing major hospitals before opening others that could replace them (...). In what can be seen as a gross conflict of interest, he is also the owner of private hospitals, which are in direct competition with public facilities. His most disastrous move was to close the Emergency Room at a major children's hospital in Khartoum, claiming that this was to ensure that patients went to hospitals closer to their homes (...). Doctors say this was catastrophic for child emergency care, as the other ERs to which the cases were directed did not have the same facilities and were few and far between. Humeida's support for privatization and a de-centralisation of medical care is typical of the way government public spending is run in the country. Many spending policies are made under benign banners such as efficiency and re-distribution. But they are in effect furtive shimmies that allow the government to lift subsidies, spend less on public services, and to plunder them when needed, selling off land or property, or simply cutting off spending altogether, and passing the cost on to the citizen. Mamoun Humeida is a problematic figure who exemplifies the new shape of power in the country - the businessman politician: a sort of private-public mix of commercial heft and government loyalty who blurs the lines between the personal and public purse. Promoting his own interests, as well as the government's need to privatize, because of its lack of funds. ${ }^{21}$

In the light of observations such as these, and in the context of fistula in particular, privatization cannot fight the social and medical ramifications: as it affects poor and particularly vulnerable populations, the issue of fistula is not a "profitable one" for medical facilities ${ }^{22}$.

Moreover, the problem of fistula specifically needs a proactive public policy that would include the training of midwives and surgeons, quality equipment, improvements in maternal healthcare, and community outreach to remote areas. Doctors also need incentives, as surgery can be long and risky. ${ }^{23}$ In Sudan today, many doctors are not interested in practicing this type of surgery, and it is often performed pro bono by surgeons, as a practitioner we interviewed confirmed to us.

The links between global and local translates into the fact that the issue of fistula within the public health services sector is one of those topics that attract particular support from NGOs and foundations. Thus, in 2003, UNFPA and its partners launched a global campaign to end fistula, and included

21. Malik, N. 2014.

22. However, investment in it might occur if it were to fall under the umbrella of UHC universal health coverage.

23. The fistula surgery can take from 30 minutes to two hours (in the complicated cases). 
among these partners are a number of large international organizations that can provide significant funds for the fight against fistula. In its annual reports, for example, the Fistula Foundation indicates that it helps fund fistula surgery, surgeon training, equipment, and community outreach in Sudan ${ }^{24}$. As the reports also indicate, this support was channelled through the Women and Health Alliance International (WAHA), an NGO based in France, to support three Sudanese medical facilities: Kassala and Nyala Hospitals in an amount of 200,000 USD in 2012, and Dr Abbo's centre in an amount of 185,800 USD in 2013 and 137,710 USD in 201125. Moreover, in 2015, the World Health Assembly launched the "G4 Alliance", the Global Alliance for Surgical, Obstetric, Trauma, and Anaesthesia Care. This coalition of organizations, "is committed to advocating for the neglected surgical patient and is driven by a mission of providing a collective voice for increasing access to safe, essential and timely surgical, obstetric, trauma and anaesthesia care as part of universal health coverage". This new initiative in the field of obstetric care also helps fund the fight against fistula in developing countries such as Sudan.

Despite the ease of attracting foreign funds, which is to be commended, one must be aware that this profusion of money can have negative reverberations. Interest on the part of international stakeholders may result in what we hypothesize to be the government unfortunately renouncing its expenditure responsibilities in support of the fight against fistula, and by so doing succeeding in saving money. This might also be motivated by the government's interest in including fistula surgery within the private sector.

Whatever the reasons, a decline in government involvement as a mechanism has been observed in various sectors in other countries. In his history of the Congo, Van Reybrouck explains how in the 2000s, President Joseph Kabila was able to reduce public expenses in several areas - public health, agriculture, and education - in which international donors were particularly invested (Van Reybrouck 2012: 606). This also leads to a decline in public participation by civil society whereby the ongoing dismantling of health services is masked by the compensatory action of NGOs and foundations, and becomes invisible to the public eye.

Besides the two aforementioned issues of social marginalization and lack of profitability of fistula surgery, one must also stress the "gender" component of the fistula issue, as this aspect also seems to partly explain its neglect on the part of the government. Not only is fistula a problem that affects the female body, but it is also the result of a whole range of violent acts directed against women, such as early marriage, neglect of maternal health and female genital mutilation.

In the Darfur region, for example, where many women are affected by obstetric fistula, early marriage is widespread. According to the UNFPA, "field

24. Fistula Foundation.

25. Ibid. 
workers have expressed concern that in IDP camps mothers perceive early marriage as a means of protection. They do not want their daughters to run the risk of rape and sexual violence while conducting daily routines such as firewood collection, and then not be marriageable. They prefer to marry them off as young as possible noting that in Sudan the legal age of marriage for girls is 10 years. Poverty is another reason to marry off daughters at a young age since marriage equals income from the dowry and one mouth less to feed" (2014).

To conclude, it seems highly plausible that Dr Abbo's Fistula Centre was demolished because it was not used by people living in the capital, but by socially marginalized women from remote areas. Although, as in the case of the research conducted by Hind Mahmoud in 2005, many studies have shown the consequences of fistula in terms of stigmatization in sufferers' lives, new research could usefully be conducted to investigate the role of gender inequalities, and more widely of social marginalization, in the way governments address the problem of fistula as compared to other health problems.

\section{BIBLIOGRAPHY}

\section{Scientific publications:}

Ahmed, E. and Marchal, R., 2007, "Soudan: Fonctionnement et pratiques du pouvoir de Khartoum; leviers d'action pour la communauté internationale. Le Parti du Congrès National à l'épreuve des urnes ", EPMES, no. 108, Channel Research, p. 32.

Abusharaf, 2007, R. M., Female Circumcision: Multicultural Perspectives, Pennsylvania Studies in Human Rights.

Babiker, M., January 1996, The impact of liberalization policies on health. Some evidence from Sudan.

Boddy, J., 2007, Civilizing Women: British Crusades in Colonial Sudan, Princeton University Press.

Cowgill, K. D., Bishop, J., Norgaard, A. K., Rubens, C. E., \& Gravett, M. G., 2015. Obstetric fistula in low-resource countries: an under-valued and under-studied problem - systematic review of its incidence, prevalence, and association with stillbirth. BMC Pregnancy and Childbirth, 15, 193. http://doi.org/10.1186/s12884-015-0592-2

El Dareer, A., 1982, "Woman, why do you weep? Circumcision and its consequences", Zed Books Ltd.

Gruenbaum, E. 2015, "From harmful traditions" to "pathologies of power": re-vamping the anthropology of health in Sudan, in "Fifty years of anthropology in Sudan: past, present and future", Past, Present and Future. Fifty years of Anthropology in Sudan, CMI (Chr. Michelsen Institute).

Khalil, A., 2011, A Review of Obstetric Fistula in Sudan, Obstetrics and Gynecology. 
Mann, L., 2014, "Wasta! The Long-term Implications of Education Expansion and Economic Liberalisation on Politics in Sudan", Review of African Political Economy 41 (142).

Toubia, N., 1994, Female Circumcision as a Public Health Issue, The New England Journal of Medicine.

Van Reybrouck, D., 2012, Congo une histoire, Actes Sud.

Wall L.L., 2012, Obstetric Fistula Is a "Neglected Tropical Disease". PLoS Negl Trop Dis 6(8): e1769. doi:10.1371/journal.pntd.0001769

Newspaper articles:

Sudan Tribune, 9 July 2013, Khartoum State Health Minister Assaulted by Medical Doctor, http://www.sudantribune.com/spip.php?article47239, accessed 15/05/2016.

Sudan Vision, 8 August 2013, Doctors Reject Jafar Ibn Auf Hospital Closing, http://news.sudanvisiondaily.com/details.html?rsnpid=218084, accessed 28/06/2016.

Sudan Vision, 31 August, 2015, "UNFPA in Sudan has a Strong Partnership and Expanded Alliances with Wide Range of Stakeholders, UNFPA Representative", http://news.sudanvisiondaily.com/details.html?rsnpid= 254172, accessed 10/05/2016.

\section{Websites:}

Malik, N., 2014,"Failing hospitals and private-public fiefdoms: what healthcare reveals about Sudan", African Arguments. http://africanarguments. org/2014/11/13/failing-hospitals-and-private-public-fiefdoms-what-healthcare-reveals-about-sudan-by-nesrine-malik/, accessed 10/05/2016.

WAHA, http://www.waha-international.org/?what-we-do=1269\&sudan-waha-topartner-with-khartoum-teaching-hospital-to-increase-fistula-treatment, accessed 12/04/2016.

Fistula Foundation, https://www.fistulafoundation.org/countries-we-help/sudan/, https://www.fistulafoundation.org/what-is-fistula/, accessed 12/04/2016.

\section{UN/NGO/foundations reports:}

Fistula Foundation, Annual Reports.

Public Health Institute, May 2014, Health financing system, Review report. UNFPA, 2014, Fistula Prevention and Management - Darfur. 